\title{
THE RELATIONSHIP BETWEEN EXTREME PRECIPITATION AND SURFACE AIR TEMPERATURE IN BANGLADESH
}

\author{
Ram Chandra SARKER ${ }^{1}$, Masashi KIGUCHI ${ }^{2}$, Nobuyuki UTSUMI ${ }^{3}$, Kazuo OKI ${ }^{4}$ \\ and Taikan $\mathrm{OKI}^{5}$ \\ ${ }^{1}$ Student Member of JSCE, M. Eng., Department of Civil Engineering, The University of Tokyo \\ (4-6-1, Meguro-ku, Komaba, Tokyo 153-8505, Japan) \\ ${ }^{2}$ Member of JSCE, Dr. of Sci., Special-Appointed Asst. Prof., Institute of Industrial Science, The University of \\ Tokyo (4-6-1, Meguro-ku, Komaba, Tokyo 153-8505, Japan) \\ ${ }^{3}$ Member of JSCE, M. Eng., Project Researcher, Institute of Industrial Science, The University of Tokyo \\ (4-6-1, Meguro-ku, Komaba, Tokyo 153-8505, Japan) \\ ${ }^{4} \mathrm{PhD}$ in Urban and Regional Planning, Assoc. Professor, Institute of Industrial Science, The University of Tokyo \\ (4-6-1, Meguro-ku, Komaba, Tokyo 153-8505, Japan) \\ ${ }^{5}$ Member of JSCE, Dr. of Eng., Professor, Institute of Industrial Science, The University of Tokyo \\ (4-6-1, Meguro-ku, Komaba, Tokyo 153-8505, Japan)
}

\begin{abstract}
This study aims exploring the characteristics of extreme precipitation corresponding to surface air temperature in Bangladesh. Analysis for each seven division of Bangladesh has been accomplished separately using observation dataset. In the next step, calibration of historical extreme precipitation from GCM model MIROC simulation has been performed comparing with observation. Model simulated dataset is obtained from the scenario of RCP8.5 of MIROC version-5. Bias correction has been taken into consideration while using model output. Finally, model simulation is applied to analyze projection of future changes of extreme precipitation in the targeted region. Results show that there are fair agreement among observation, MIROC present and MIROC projection simulations. An increase in extreme precipitation intensity is found in six divisions among seven divisions in Bangladesh for MIROC future projection simulation.
\end{abstract}

Key Words : Clausius-Claypeyron Relation, MIROC, RCP8.5

\section{INTRODUCTION}

Precipitation plays a crucial role in global hydrological cycle. Extreme precipitation has a huge influence on society. They are associated with flood disaster, erosion, water damage, and may have serious impacts on transport and safety. In fact, extreme hydro meteorological events' intensified by climate change due to nature and anthropogenic activity is a great concern for present society ${ }^{1,2), 3), 4}$. It is expected that the intensity of extreme precipitation will increase as the climate warms ${ }^{5)}$. Precipitation intensity is projected to increase in most regions under warmer climates, and the increase in precipitation extremes will be larger than that in the mean precipitation ${ }^{4), 6}$. The primary reason for this expectation is that the maximum moisture content of the atmosphere increases with approximately $7 \%$ per degree temperature rise, which follows the Clausius-Clapeyron (C-C) relation ${ }^{7}$. The increase in the atmospheric water holding capacity associated with a temperature increase (described by the $\mathrm{C}-\mathrm{C}$ relation) considerably influences the changes in the extreme precipitation intensity under warmer climate ${ }^{4), 7), 8}$. An increase of daily precipitation extremes is found compare to at rate predicted by the C-C relation ${ }^{9), 10}$. It is still not clear that why changes in precipitation extremes should follow a C-C scaling. However, changes in the atmospheric large scale motions ${ }^{7,11)}$, the moist-adiabatic lapse rate ${ }^{7,12)}$, the dynamics of the clouds ${ }^{7,8)}$ and limitations in moisture increase due to soil water depletion ${ }^{7), 13)}$ may result in deviations from a C-C scaling. Behavior of extreme 


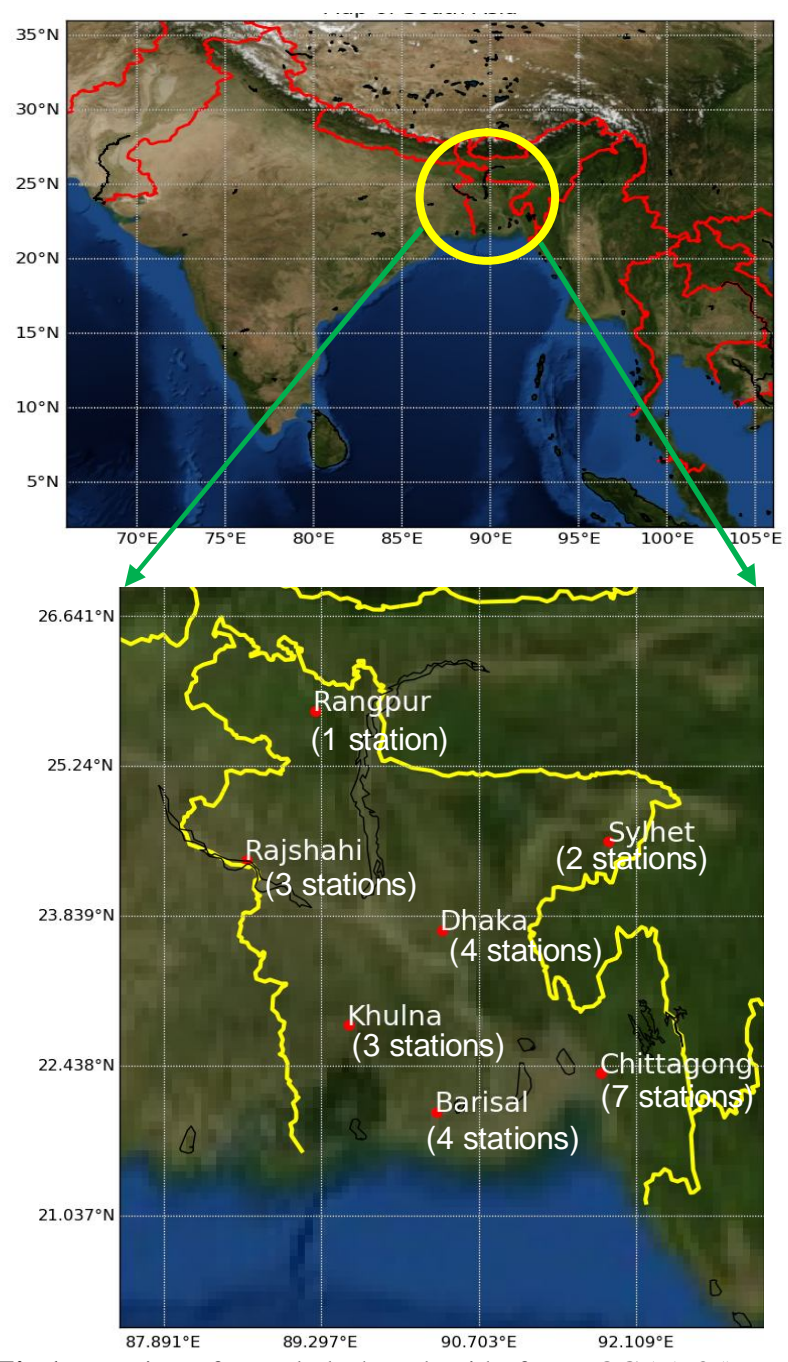

Fig.1 Location of Bangladesh and grid of MIROC5 (T85) over Bangladesh and position of centre district of seven divisions.

precipitation was investigated six countries excluding Bangladesh ${ }^{4)}$.

Furthermore, Bangladesh is very prone to flooding due to its location at the confluence of the Ganges, Brahmaputra and Meghna (GBM) rivers and because of the hydro-meteorological and topographical characteristics of the basins in which it is situated. Eighty percent of the annual rainfall occurs in the monsoon (June-September) across the river basins and extreme flood events occurred due to excessive rainfall in the catchments ${ }^{14)}$. That is why extreme precipitation has its influence in flood disaster in Bangladesh. Hence study on extreme precipitation can result in better understanding of rainfall characteristics and contribution to society. To prevent the heavy rain disasters, it is necessary to know the characteristics of heavy rain in a better way. Also, it is a good idea to know about the impact of global warming on heavy rainfall which is likely expected off, is an important theme in social science. Hence, relationship between extreme precipitation and global warming are under discussion.

\section{STUDY AREA AND DATASET}

\section{(1) Study area}

Study area in this work covers whole Bangladesh in south Asia. Bangladesh is located between $20^{\circ} 34^{\prime}$ to $26^{\circ} 38^{\prime}$ North latitude and $88^{\circ} 01^{\prime}$ to $92^{\circ} 42^{\prime}$ East longitude. It is a low-lying and riverine country bordered on the west, north and east by India, on the south-east by Myanmar (Burma) and on the south by the Bay of Bengal. Fig.1 shows the location of Bangladesh in south Asia.

\section{(2) Dataset}

Two kinds of datasets are used in this work namely in-situ dataset of Bangladesh and model MIROC $^{15)}$ simulated dataset. MIROC stands for the Model for Interdisciplinary Research On Climate (MIROC), which is the coupled general circulation model (GCM).

\section{a) In-situ dataset}

In-situ dataset as an observation dataset, collected from Bangladesh Meteorological Department (BMD) has been used for analyzing present extreme precipitation and after that it has compared with the MIROC model simulated dataset for calibration. There are 34 Rain gauge stations in Bangladesh. Bangladesh has seven major administrative divisions namely Dhaka (The Capital), Rajshahi, Rangpur, Sylhet, Chittagong, Barisal and Khulna. The considered number of rain gauge stations per division based on available in-situ dataset has been shown in Fig.1 in parenthesis just below the name of the each division. Analysis for each division has been performed separately in this study.

\section{b) MIROC dataset}

MIROC dataset is obtained from the simulation of MIROC5 (version-5) ${ }^{15)}$ GCM model. In this study scenario RCP8.5 (Representative Concentration Pathway) ${ }^{16), 17)}$ has been considered for analysis for future. Spatial resolution for T85 MIROC5 data is about $150 \mathrm{~km}$. MIROC dataset is used for calibration with in situ dataset as well as for future projection. The time period $1950-1999$ is used for calibration and $2051-2100$ is for future projection. The location and grid positions of seven divisions of Bangladesh are shown in Fig.1.

\section{METHODOLOGY}

We use daily average surface air temperature $\left({ }^{\circ} \mathrm{C}\right)$ and daily precipitation ( $\mathrm{mm} /$ day) for analyzing behavior of extreme precipitation. Dependencies of daily precipitation intensity on the surface air temperature are computed using a binning technique ${ }^{18), 19)}$. Binning is done in classes of $1{ }^{\circ} \mathrm{C}$ 


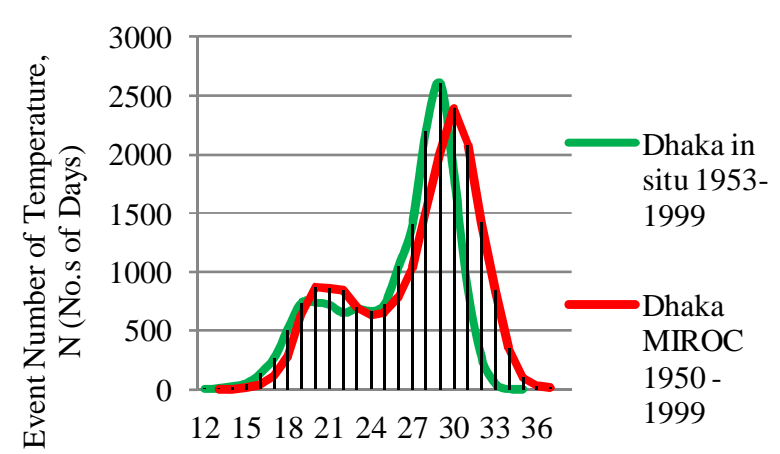

Surface Air Temperature, $\mathrm{T}$

$\left({ }^{\circ} \mathrm{C}\right)$

Fig.2 Temperature distribution curve for estimating bias error of MIROC simulation with respect to in-situ surface air temperature for Dhaka.

width. From the binned data different percentiles are computed from the distribution of wet events. As stated in dataset chapter, analysis is subdivided into seven parts that means for each division analysis will be accomplished. $99^{\text {th }}$ percentile precipitation is used as an index of extreme precipitation in this study. Statistically, the $99^{\text {th }}$ percentile is the smallest number that is greater than $99 \%$ of the numbers in a given set. So the highest $1 \%$ precipitation among a precipitation dataset can be considered as $99^{\text {th }}$ percentile precipitation. Here temperature means daily average surface air temperature.

Temperature Distribution Curve (TDC) is the curve that represents relation between temperature and no. of days of that specific temperature over a period of time. By comparing TDC (Fig.2) of in-situ and MIROC, if we get some deviation of MIROC simulated data over in-situ data, this deviation is defined here as bias error in model MIROC simulated dataset. Actual bias error can be obtained from the difference of mean temperature of MIROC and observation which can be expressed as Eq.(1a).

$$
\text { Bias Error }=\mathrm{T}_{(\text {mean MIROC) }}-\mathrm{T}_{(\text {mean Obs. })}
$$

Where, $\mathrm{T}_{\text {(mean MIROC) }}$ means mean temperature of MIROC, $\mathrm{T}_{\text {(mean Obs.) }}$ means mean temperature of observation. Mean can be calculated as the summation of $\mathrm{N}$ (event number) and $\mathrm{T}$ (temperature) over total N. For positive bias the temperature dataset obtained from MIROC simulation should be corrected by deducting by the amount of bias error while computation of $99^{\text {th }}$ percentile (p99) curve of MIROC simulation. As a result p99 curve will be shifted to backward. The purpose of doing bias correction is to do the calibration of MIROC simulated dataset with a view to getting more realistic dataset for comparing with in-situ dataset results.
Table 1 Bias correction for each division.

\begin{tabular}{|c|c|}
\hline Division & Bias Error $\left({ }^{\circ} \mathrm{C}\right)$ \\
\hline Barisal & 0.88 \\
\hline Chittagong & -0.15 \\
\hline Dhaka & 1.36 \\
\hline Khulna & 0.78 \\
\hline Rajshahi & 1.29 \\
\hline Rangpur & -2.23 \\
\hline Sylhet & 1.48 \\
\hline
\end{tabular}

First the observational extreme precipitation has been analyzed. Furthermore, the MIROC model output dataset has been analyzed along with bias correction. After that the observation and model result is compared to evaluate the performance of model MIROC. If there any bias error in MIROC model, an attempt to overcome that error is being accomplished. After validation of MIROC present and observation dataset, an attempt of future projection for extreme precipitation has been executed for the targeted region.

\section{RESULTS}

Fig.2 shows the temperature distribution curve of daily average surface air temperature of model simulated dataset (red curve) over Dhaka region and that of in-situ dataset (green curve) of Dhaka region. There is a deviation of about $1{ }^{\circ} \mathrm{C}$ in TDC of MIROC simulated dataset from in-situ dataset. This deviation is defined here as Bias Error in model MIROC but actual bias error can be estimated using Eq (1a) described in methodology section. Using Eq (1a) the calculated actual bias error for Dhaka is found as $1.36{ }^{\circ} \mathrm{C}$. It means that we should consider $1.36{ }^{\circ} \mathrm{C}$ warmer states when we consider MIROC simulated dataset. During calibration we have used this bias error. Table 1 shows the calculated actual bias error for each division. Bias correction has been considered for model output from MIROC. Negative value indicates that temperature dataset from MIROC simulation is less warm than that of observation dataset.

Fig.3 represents the relationship between daily extreme precipitation and daily average surface air temperature obtained by analyzing the in-situ dataset of Dhaka division. This curve is yearly trend of extreme precipitation. Vertical primary axis (left) is $99^{\text {th }}$ percentile precipitation in $\mathrm{mm} /$ day in logarithmic scale. Vertical secondary axis (right) is for number of rainfall events. Green solid line represents trend of $99^{\text {th }}$ percentile precipitation with respect to temperature. Green dash line is for average yearly rainfall. Green solid bars represent number of rainfall events for that specific temperat- 

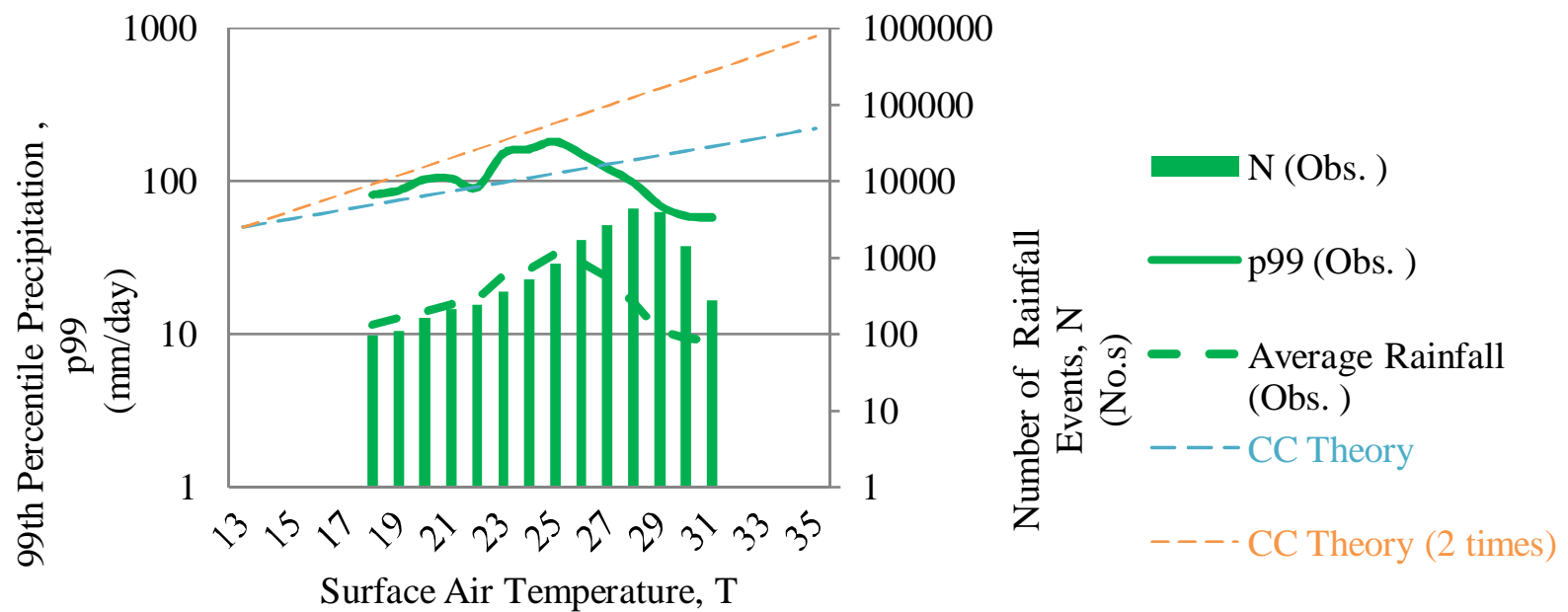

$\left({ }^{0} \mathrm{C}\right)$

Fig.3 Trend of extreme precipitation for in-situ dataset of Dhaka division (four stations) during period 1950-1999. N means number of rainfall events, $\mathrm{p} 99$ means $99^{\text {th }}$ percentile precipitation in $\mathrm{mm} / \mathrm{day}$.

-ure. Blue thin dash line is used as reference of C-C relation. Orange thin dash line is 2 times C-C theory line. The purpose of using $\mathrm{C}-\mathrm{C}$ lines here is to compare the rate of increase of observational extreme precipitation with the theoretical one because the maximum moisture content of the atmosphere increases with approximately $7 \%$ per degree temperature rise, which follows the Clausius-Clapeyron (C-C) relation ${ }^{7)}$ as described in introduction section. Observation dataset ranges from the year of 1950 to 1999 . The result shows that extreme precipitation (daily) trend start with ascending trend similar to $\mathrm{C}-\mathrm{C}$ relation up to certain limit (around $25^{\circ} \mathrm{C}$ ) but the rate of increase of ascending trend of extreme precipitation is higher (about 2 to 3 times) than $\mathrm{C}-\mathrm{C}$ relation before breaking point. After the breaking point precipitation trend declines downward for the daily observed rainfall. After breaking point why it is declining still it is not clear from this research.

In Fig.4, the horizontal axis is daily average surface air temperature in ${ }^{\circ} \mathrm{C}$. Vertical (left) primary axis is $99^{\text {th }}$ percentile precipitation in $\mathrm{mm} /$ day in logarithmic scale. Vertical secondary axis (ordinate) is for number of rainfall event. Solid lines represent trend of $99^{\text {th }}$ percentile precipitation (p99) with respect to daily average surface air temperature. Dash lines are for average yearly rainfall. Solid bars represent corresponding number of rainfall event of p99. Green color represents in-situ dataset of Dhaka division (four stations) for the time period year of 1950 to 1999. Red color represents MIROC present dataset (bias corrected) for the time period year of
1950 to 1999. Blue color represents MIROC projection (bias corrected) for the time period year of 2051 to 2100. Blue thin dash lines are used as reference of $\mathrm{C}-\mathrm{C}$ relation. Orange thin dash line is 2 times $\mathrm{C}-\mathrm{C}$ theory line.

In Fig.4, first of all, there are similarities in the pattern of p99 of observation, MIROC present and MIROC projection. In fact, p99 curve of observation (green curve) and that of MIROC present simulation (red curve) have fair agreement. Also MIROC present simulation (red curve) and MIROC future simulation (blue curve) have fair agreement. So, logically we can relate observation result to MIROC future projection simulation. In this way, for future projection MIROC dataset can be applied for the assessment of characteristics of extreme precipitation for Dhaka region using comparisons among these three curves. Furthermore, the peak of p99 of MIROC and that of observation differ to some marginal extent in daily temperature. In addition, the peak of p99 and number of rainfall event (green, red and blue columns) differ to some extent for observation, MIROC present and MIROC projection. Even number of rainfall event is still increasing while the curve declines downward for all three lines. So, the trends of extreme precipitation cannot be explained by the corresponding rainfall event numbers. Also, for future projection of MIROC, rainfall event numbers (blue columns) are found in higher temperature than observation (green columns). It implies that rainfall may occur more in future for higher temperature compared to present observation rainfall. 


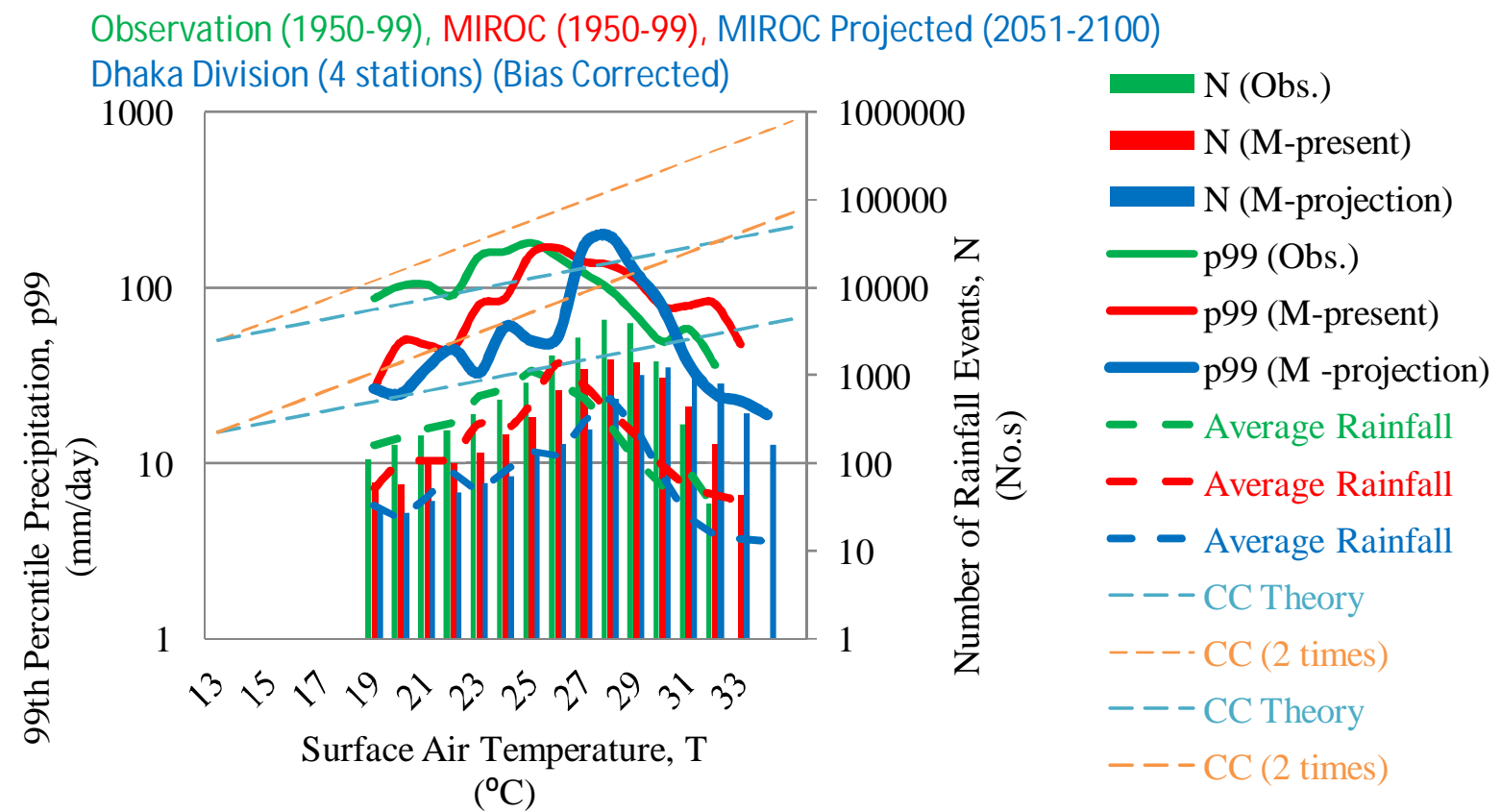

Fig.4 Comparison between MIROC (bias corrected) \& observation, and future projection of MIROC simulation (bias corrected) for Dhaka division. $\mathrm{N}$ means number of rainfall events, p99 means $99^{\text {th }}$ percentile precipitation in $\mathrm{mm} /$ day. If rainfalls are not successive within one day, the rainfall event will be the cumulative rainfall for that specific day.

Moreover, results of MIROC simulation produces lower magnitude compared to observational extreme precipitation. There may have several reasons behind that. One of them could be the difference in spatial resolution of MIROC T85 (about $150 \mathrm{~km}$ ) and cumulus cloud $(<10 \mathrm{~km})$. That is why, the projection of MIROC for 21th century may produce lower value of extreme precipitation than that of in practical field. Least but not last, Fig.4 represents validation of historical extreme precipitation from GCM model MIROC5 simulation by comparing with observation, and projection of model simulation for future changes of extreme precipitation in the targeted region of Dhaka division. Table 2 shows the summary of future projection of model simulation for seven divisions of Bangladesh. Change ratio of peak of p99 ranges from $-13 \%$ to $45 \%$ for seven divisions in Bangladesh from which we found an increase in extreme precipitation intensity in six divisions among seven divisions in MIROC future projection simulation.

\section{CONCLUSIONS}

Extreme precipitation (daily) trend is similar to ascending trend of $\mathrm{C}-\mathrm{C}$ relation up to certain limit or breaking point (around $25^{\circ} \mathrm{C}$ ) with higher rate (about 2 to 3 times) but after breaking point trend declines downward for the daily observed rainfall.
Table 2 Peak of temperature, p99 and change ratio of peak of p99 of future projection of model simulation for seven divisions in Bangladesh.

\begin{tabular}{|c|c|c|c|c|}
\hline \multicolumn{1}{|c|}{} & $\begin{array}{c}\text { Peak } \\
\left({ }^{0} \mathrm{C}\right)\end{array}$ & $\begin{array}{c}\text { Peak } \\
\text { of p99 } \\
(\mathrm{mm})\end{array}$ & $\begin{array}{c}\text { Change } \\
\text { ratio of } \\
\text { peak of } \\
\text { p99 }(\%)\end{array}$ \\
\hline \multirow{3}{*}{ Barisal } & Obs. & 25 & 207 & - \\
\cline { 2 - 5 } & M-Pre. & 26 & 175 & - \\
\cline { 2 - 5 } & M-Proj. & 29 & 178 & 2 \\
\hline \multirow{4}{*}{ Dhittagong } & Obs. & 25 & 229 & - \\
\cline { 2 - 5 } & M-Pre. & 26 & 168 & - \\
\cline { 2 - 5 } & M-Proj. & 28 & 147 & -13 \\
\hline \multirow{3}{*}{ Khulna } & Obs. & 25 & 180 & - \\
\cline { 2 - 5 } & M-Pre. & 26 & 169 & - \\
\cline { 2 - 5 } & M-Proj. & 28 & 197 & 17 \\
\hline \multirow{3}{*}{ Rajshahi } & Obs. & 25 & 192 & - \\
\cline { 2 - 5 } & M-Pre. & 27 & 167 & - \\
\cline { 2 - 5 } & M-Proj. & 28 & 183 & 10 \\
\hline \multirow{3}{*}{ Rangpur } & Obs. & 25 & 179 & - \\
\cline { 2 - 5 } & M-Pre. & 26 & 106 & - \\
\cline { 2 - 5 } & M-Proj. & 27 & 154 & 45 \\
\cline { 2 - 5 } & Obs. & 25 & 188 & - \\
\cline { 2 - 5 } & M-Pre. & 26 & 156 & - \\
\cline { 2 - 5 } Sylhet & M-Proj. & 28 & 193 & 24 \\
\hline & Obs. & 23 & 217 & - \\
\cline { 2 - 5 } & M-Pre. & 24 & 134 & - \\
\cline { 2 - 5 } & M-Proj. & 26 & 174 & 30 \\
\hline
\end{tabular}

Obs.=Observation, M-Pre. $=$ MIROC Present, M-Proj. $=$ MIREOC Projection 
For future projection MIROC dataset can be applied for the assessment of characteristics of extreme precipitation in tropical region like Bangladesh, though future climate projection includes uncertainty. Although we can use MIROC as an assessment tool, indeed. The trends of extreme precipitation cannot be explained by the rainfall event numbers. MIROC simulations show somewhat low magnitude of peak of p99 of MIROC present extreme precipitation compare to observed extreme precipitation. Maximum 45\% increase in extreme precipitation (peak) is projected by MIROC future projection for Rajshahi among the seven divisions.

Analysis of hourly extreme precipitation for this targeted region including the impact of extreme precipitation on flood disaster can be the extension of this research. In addition, comparison between moisture content in atmosphere and surface air temperature can be a topic to carry out further research along with reason of declining after breaking point.

ACKNOWLEDGMENT: This research was supported by the Environment Research and Technology Development Fund (S-10) of the Ministry of the Environment, Japan. Authors are also grateful to the Asian Development Bank Japan Scholarship Program (ADB-JSP) for financial support and equally grateful to the Japan International Corporation Agency (JICA), Japan; Kyoto University, Japan; Bangladesh Meteorological Department (BMD) for providing in-situ dataset to accomplish this research work.

\section{REFERENCES}

1) Oki, T., and Shinjiro, K.: Global hydrological cycles and world water resources. Science, 313, 1068-1072, doi:10.1126/science.1128845, 2006.

2) Pall, P., Aina, T., Stone, D. A., Stott, P. A., Nozawa, T., Hilberts, A. G. J., Lohmann, D., and Allen, M. R.: Anthropogenic greenhouse gas contribution to flood risk in England and Wales in autumn 2000. Nature, 470, 382-385, doi:10.1038/nature09762, 2011.

3) Min, S., Zhang, X., Zwiers, F. W., and Hegerl, G. C.: Human contribution to more intense precipitation extremes. Nature, 470, 378-381, doi:10.1038/nature09763, 2011.

4) Utsumi, N., Seto, S., Kanae, S., Maeda, E. E., and Oki, T.: Does higher surface temperature intensify extreme precipitation? Geophysical research letters, Vol. 38, L16708, doi:10.1029/2011GL048426, 2011.

5) IPCC: Climate Change 2007: The Physical Science Basis. Contribution of Working Group I to 15 the Fourth Assessment Report of the Intergovernmental Panel on Climate Change (IPCC), edited by: Solomon, S., Qin, D., Manning, M., Chen, Z., Marquis, M., Averyt, K. B., Tignor, M., and Miller, H. L., Cambridge University Press, Cambridge, UK and New York, NY, 4702, 2007.

6) Meehl, G. A., et al.: Global climate projections, in Climate Change 2007: The Physical Science Basis. Contribution of
Working Group I to the Fourth Assessment Report of the Intergovernmental Panel on Climate Change, edited by S. Solomon et al., pp. 747-845, Cambridge Univ. Press, Cambridge, U. K, 2007.

7) Lenderink, G., Mok, H. Y., Lee, T. C., and van Oldenborgh G. J.: Scaling and trends of hourly precipitation extremes in two different climate zones - Hong Kong and the Netherlands. Hydrol. Earth Syst. Sci. Discuss., 8, 4701-4719, www.hydrol-earth-syst-sci-discuss.net/ 8/4701/ 2011/ doi:10.5194/hessd-8-4701-2011, 2011.

8) Trenberth, K. E., Dai, A., Rasmussen, R., and Parsons, D.: The changing character of precipitation., B. Am. Meteorol. Soc., 84, 1205-1217, 4703, 4704, 2003.

9) Allen, M. R. and Ingram,W. J.: Constraints on the future changes in climate and the hydrological cycle. Nature, 419, 224-232, 4703, 2002.

10) Pall, P., Allen, M., and Stone, D.: Testing the Clausius-Capeyron constraint on changes in extreme precipitation under $\mathrm{CO} 2$ warming. Climate Dynam., 28, 351-363, 4703, 2007.

11) Emori, S. and Brown, S. J.: Dynamic and thermodynamic change in mean and extreme precipitation under climate change. Geophys. Res. Lett., 32, L17706, doi:10.1029/2005GL023272, 4703, 2005.

12) O'Gorman, P. A. and Schneider, T.: The physical basis for increases in precipitation extremes in simulations of 21st-century climate change. P. Natl. Acad. Sci. USA, 106, 14773-14777, available at: http://www.pnas.org/content/106/35/14773.abstract, 4703, 2009.

13) Berg, P., Haerter, J. O., Thejll, P., Piani, C., Hagemann, S., and Christensen, J. H.: Seasonal characteristics of the relationship between daily precipitation intensity and surface temperature. J. Geophys. Res., 114, D18102, doi:10.1029/2009JD012008, 4703, 4704, 2009.

14) Hossain, A.N.H. A.: BANGLADESH: FLOOD MANAGEMENT, WMO/GWP Associated Programme on Flood Management, 2003.

15) Watanabe, M., Suzuki, T., O'ishi, R., Komuro, Y., Watanabe, S., Emori, S., Takemura, T., Chikira, M., Ogura, T., Sekiguchi, M., Takata,K., Yamazaki, D., Yokohata, T., Nozawa, T., Hasumi, H., Tatebe, H., and Kimoto, M.: Improved Climate Simulation by MIROC5: Mean States, Variability, and Climate Sensitivity. Journal of Climate. doi: 10.1175/2010JCLI3679.1, 2011.

16) van Vuuren, D. P., Edmonds, J., Kainuma, M., Riahi, K., Thomson, A., Hibbard, K., Hurtt, G. C., Kram, T., Krey, V., Lamarque, J-F., Masui, T., Meinshausen, M., Nakicenovic, N., Smith, S. J., and Rose, S. K.: The representative concentration pathways: an overview, Climatic Change 109:5-31, doi 10.1007/s10584-011-0148-z, 2011.

17) Riahi, K., Rao, S., Krey, V., Cho, C., Chirkov, V., Fischer, G., Kindermann, G., Nakicenovic, N., and Rafaj, P.: RCP 8.5-A scenario of comparatively high greenhouse gas emissions. Climatic Change 109:33-57, doi 10.1007/s10584-011-0149-y, 2011.

18) Lenderink, G. and van Meijgaard, E.: Increase in hourly precipitation extremes beyond expectations from temperature changes. Nat. Geosci., 1, 511-514, doi:10.1038/ngeo262, 4704, 4705, 4706, 2008.

19) Lenderink, G. and van Meijgaard, E.: Linking increases in hourly precipitation extremes to atmospheric temperature and moisture changes. Environ. Res. Lett., 5, 025208, available at: http://stacks.iop.org/ 1748-9326/5/i=2/a=025208, doi:10.1088/1748-9326/5/2/ 025208, 4704, 4705, 4706, 4707, 4711, 2010.

(Received September 30, 2012) 